\title{
INTERNAL SABOTEURS AND WORK PERFORMANCE - IMPLICATIONS FOR HRM PRACTICES
}

\author{
Cătălina $R A D U^{a^{*}}$
}

${ }^{a}$ Bucharest University of Economic Studies, Romania

\begin{abstract}
This study aims to analyze the relationship between internal saboteurs developed since childhood and job performance, with implications for HRM practices - especially in terms of selection criteria to be used and the whole assessment process. The study was conducted through an online questionnaire which was made available in March-April of 2021. The analyzed instruments are Shirzad Chamine's inner saboteur questionnaire and Goodman \& Syvantek's Job Performance Scale. The study was performed on a 457-respondent non-probabilistic cohort. Statistical analysis of the data revealed that some internal saboteurs are oriented toward performance, while the others are oriented toward emotion. The performance-oriented cluster seemed to predominate in male respondents, while the emotion-oriented cluster seemed to predominate in female respondents, in line with tradintional gender roles. The main findings are generally in line with previous literature, and they are also suggesting a series of HRM practices aimed at increasing individual and organizational performance.
\end{abstract}

KEYWORDS: gender differences, HRM practices, positive intelligence, work performance.

\section{INTRODUCTION}

Human resource management is a key asset in any organization. Therefore, in order to become more competitive, organizations emphasize the role of people. Moreover, many recent studies have focused on the idea of wellbeing, as a key factor of enhancing the organizational performance, with worker attitudes and behavior influencing performance.

This paper aims to analyze the relationship between internal saboteurs developed since childhood and job performance, with implications for HRM practices - especially in terms of selection criteria to be used and the whole assessment process.

\section{WORK PERFORMANCE, POSITIVE INTELLIGENCE AND INTERNAL SABOTEURS - A BRIEF LITERATURE REVIEW}

\subsection{Work Performance and High-Performance HR Practices}

Performance is a goal for each of us, whether we are talking about our performance as individuals, or that of the team we belong to. Although performance is a very important concept, the comprehensive conceptual framework of work performance is quite vague; what constitutes performance differs from one position to another and as a result, there are many ways to measure work performance. Some of these measurements are objective (number of pieces produced or sold, number of days of absenteeism, etc.), others are subjective (reporting the quantity and quality of work as perceived by the employee, colleagues or supervisors).

\footnotetext{
* Corresponding author. E-mail : catalina.radu@man.ase.ro
} 
Of course, all these ways of measuring can provide valuable information, but none of them capture the complexity and full range of behaviors that constitute an employee's performance in the workplace and it is difficult to create an aggregate indicator that takes into account all these aspects (Koopmans et al., 2011).

Murphy (1989) had one of the first attempts to define the concept of job performance by referring to its components (four dimensions):

- task behaviors;

- interpersonal relations (communication and cooperation with others);

- downtime behaviors (work-avoidance behaviors));

- destructive / hazarduous behaviors (leading to decreased productivity and other disadvantages).

Around the same time, Campbell (1990) created a conceptual framework made up of eight dimensions of work performance:

- job-specific task proficiency;

- non-job-specific task proficiency;

- written and oral communication;

- effort at work;

- maintaining personal discipline;

- facilitating peer and team performance;

- supervision;

- management and administration.

Another approach, simple and often used today, divides work performance into only two dimensions (Borman \& Motowidlo, 1993):

- task performance - behaviors that contribute directly or indirectly to the specifics of the organization's activities;

- contextual performance - behaviors that support the organizational, social and psychological environment in which specific activities take place (volunteering, helping peers, following the rules); they are considered discretionary behaviors, the "extra" that employers look for in extraordinary employees (Goodman \& Svyantek, 1999).

Thus, the sub-dimensions of task performance could vary between different jobs, while contextual performance encompasses aspects that, although discretionary, are rather common, regardless of the organization's field of activity (Borman \& Motowidlo, 1993; Goodman \& Svyantek, 1999).

Some authors have also paid special attention to counterproductive behaviors - absenteeism and delays, personal activities at work, or, perhaps worse, theft and substance abuse). This is the negative dimension of job performance, which translates into behaviors that harm the organization, directly or indirectly (Koopmans et al., 2011, 2014; Sinclair \& Tucker, 2006; Tucker et al., 2009). The interest in performance is normal and the focus on people in order to avoid negative effects of work investment that might lead to a decreased level of productivity, such as burnout, is also taken into account (Radu et al., 2020).

Another instrument is the one proposed by Griffin et al. (2007). According to these authors, the concept of work performance consists of three dimensions:

- profficiency - the extent to which a person performs his work tasks, according to the job description;

- adaptivity - the extent to which the employee manages to comply with changes at the workplace and associated responsibilities;

- proactivity - the extent to which the employee has initiative at the organizational level or related to their own work tasks.

Adaptability / adaptive performance has also been taken into account by other authors as a main dimension of work performance (Allworth \& Hesketh, 1999; Charbonnier-Voirin \& Roussel, 2012; Sinclair \& Tucker, 2006). 
All these instruments allow for a subjective measurement of work performance, asa it is selfperceived or perceived by other people (colleagues, managers). Moreover, even objective indicators ultimately lead to a subjectively measured overall performance, which depends on the choice of indicators, the calculation formula that brings them together and the importance coefficient given to each of them (Tangen, 2005).

Regarding self-perceived performance, such a report is very much related to the concept of selfefficacy proposed by Bandura in his social-cognitive theory of career. Thus, self-efficacy refers to people's beliefs in their ability to achieve certain levels of performance, which exerts influence on future events and situations (Bandura, 1994). In principle, people with a higher level of self-efficacy are able to successfully tackle difficult tasks and achieve their goals with a higher level of performance than those with a lower level of self-efficacy, with the latter concentrating too much on the failures they had and not trusting their own abilities (Bandura, 1995).

However, there are also studies that indicate a negative relationship between self-efficacy and performance (Austin \& Vancouver, 1996; Powers, 1991; Vancouver et al., 2001, 2002). The main explanation for such a situation is given by the difference between the predictions we make at different levels of self-efficacy. Thus, given that we are talking about a higer level of self-efficacy, our expectations for future results are higher; we expect to achieve our goals faster, better, which diminishes the effort in our present action, compared to the situation in which we do not have these expectations.

In fact, Vancouver et al. (2001) found a strong positive correlation between self-efficacy and performance when the analysis was done by comparison between people. On the other hand, in the longitudinal analysis, at the level of the same person analyzed over time, the authors observed a negative correlation between self-efficacy and subsequent performance.

The lower involvement due to an overconfidence in one's own abilities was also the finding of Stone (1994). Thus, participants with a higher level of self-efficacy were less attentive and put in less effort than those with a lower level of self-efficacy. Likewise, in a study based on normative feedback, some participants were induced the idea of a higher level of self-efficacy. As a result, they were less motivated than the other participants to make the effort necessary to increase the level of performance, which contributed to the reverse effect, a reduction in the level of performance (Bandura \& Jourden, 1991).

As in the case of performance, there are also several instruments that measure self-efficacy (Bandura, 2006; Luszczynska et al., 2005; Panc et al., 2012; Schwarzer \& Jerusalem, 1995).

High-performance HR practices, seen as systems of HR practices, aim to increase organizational effectiveness through higher engagement and focus on objectives (Mostafa, 2017; Whitener, 2001). It seems that particular typology of people might be recommended for specific jobs. Various selection criteria are taken into account in the HR practices. Several human traits might be very important for specific jobs, since individual perspectives and values do have an influence on organizational performance (Djabatey, 2012; Ekwoaba et al., 2015). Also, the entrepreneurial competence seems to be crucial for corporate competitive advantage, with intrapreneurship a key factor of innovation (Rașcă et al., 2018).

However, selection and assessment is only part of HRM practices recommended for competitive organizations. When talking about "best" HRM practices, it is impossible to provide an exhaustive list. Theriou \& Chatzoglou (2014) suggest a series of activities / criteria aimed at attaining a higher level of performance: employment security, selective hiring, high levels of teamwork and decentralization, compensation and incentives directly linked to performance, extensive training, employee involvement, internal career opportunities, broadly defined job descriptions and harmonization. All these can contribute to a higher level of performance as a result of higher commitment and higher motivation. Wellbeing is an increasingly important criterion in HR practices (Pagán-Castaño et al., 2020). 


\subsection{Positive Intelligence and Internal Saboteurs}

As expected, the capacity to ensure that wellbeing is met does not depend only to HR practices, as worker attitudes and behavior are crucial (Guest, 2002); actually, this capacity seems to be linked to a specific type of intelligence, even though it presumably overlaps with more traditionally accepted types of intelligence, such as general intelligence or emotional intelligence, and to other types of intelligence such as the ones proposed by Howard Gardner (Gardner, 1983).

Fundamentally, intelligence is the capacity to adapt to requirements, that is, to solve problems. One important problem in life is the proper management of our own psyche, with all of its quirks, kinks and brilliance. The type of intelligence tasked with the management of our psyche has been called "positive intelligence" by psychologist and neuroscientist, Shirzad Chamine. In his model, humans have nine basic "internal saboteurs" which can hinder our progress toward our goals (Chamine, 2012). These saboteurs resemble full-fledged personalities which inhabit our psyche and pull in directions inconsistent with our set path. They are: the Hyper-vigilant, the Restless, the Avoider, the Pleaser, the Victim, the Controller, the Hyper-rational, the Hyper-ambitious and the Stickler. There is a tenth universal saboteur, the Judge, which afflicts all of us, undermining our sense of selfconfidence, efficacy and safety.

Every psyche has each of these saboteurs, in varying strengths. Thus, a person who found in childhood that pleasing those around him or her would result in more well-being than otherwise would rely on pleasing others as the preferred problem-solving strategy, even in situations where this particular strategy does not work. The capacity to distinguish situations where pleasing others is a fitting strategy from those where it is ineffectual or harmful would then be part of positive intelligence.

Chamine introduces the concept of the Sage, another inner "personality" which speaks with the voice of reason and optimism (Chamine, 2012; Stangel, 2017). It is calm, and displays curiosity, empathy, creativity, a sense of direction and efficacy in the world. This Sage serves to modulate the action of the inner saboteurs. We might call it wisdom, or, in current psychological parlance, positive intelligence. Chamine considers the Sage a capability which can be cultivated, and cultivating the Sage leads to a happier life. In short, people who have a high positive intelligence, which they apply routinely, lead happier lives.

\section{RESEARCH METHODOLOGY}

\subsection{Objectives and hypotheses}

Given the overall objective of our study, we formulated three working hypotheses, as follows:

- Hypothesis 1: There is a positive correlation between the strengths of the four internal saboteurs which are oriented toward the accomplishment of objectives and work performance.

- Hypothesis 2: There is a negative correlation between the strengths of the five emotional saboteurs and work performance.

- Hypothesis 3: Some of the internal saboteurs (Controller, Hyper-achiever, Stickler and Hyperrational) tend to be stronger in men than in women, while other saboteurs (Victim, Avoider, Pleaser, Restless and Hyper-vigilant) tend to be stronger in women than in men.

\subsection{Participants}

Our study was conducted on a non-probability sample of 457 participants, according to availability. Gender distribution was not equal ( $76 \%$ women, $24 \%$ men). The participants were between 15 and 65 years old, with an average age of 30.6 years, a median age of 26 years and a standard deviation of 10.5. In table 1, we present the work profiles of the participants. 
Table 1. Work profile of participants

\begin{tabular}{|c|l|c|c|}
\hline \multicolumn{1}{|c|}{ Work profile } & Absolute frequency & Relative frequency (\%) \\
\hline 1 & Employee with management role & 81 & $17.724 \%$ \\
\hline 2 & Employee without management role & 272 & $59.519 \%$ \\
\hline 3 & Self-employed & 40 & $8.753 \%$ \\
\hline 4 & Volunteer with management role & 6 & $1.313 \%$ \\
\hline 5 & Volunteer without management role & 58 & $12.691 \%$ \\
\hline 6 & Total & 457 & $100 \%$ \\
\hline
\end{tabular}

\subsection{Instruments}

For this study, we used two questionnaires and additional demographic data.

3.3.1. Goodman \& Syvantek's Job Performance Scale

We used the questionnaire as found on the Research Central website (Iliescu, n.d.), and applied the scoring method given. We measured the internal consistency of the scale using McDonald's Omega coefficient as described in the literature (Deng \& Chan, 2017; Hayes \& Coutts, 2020; Ravinder \& Saraswathi, 2020). The results are shown in table 2. As shown, the questionnaire had a good internal consistency, and no item was removed.

Table 2. Internal consistency of Goodman \& Syvantek's Job Performance Scale

\begin{tabular}{|c|l|c|c|}
\hline & \multicolumn{1}{|c|}{ Performance type } & Number of items & McDonald's Omega coefficient \\
\hline 1 & Task performance & 9 & 0.839 \\
\hline 2 & Contextual Performance & 7 & 0.678 \\
\hline 3 & Performance (total) & 16 & 0.809 \\
\hline
\end{tabular}

\subsubsection{Chamine's 45-item internal saboteur questionnaire}

We applied McDonald's Omega coefficient to Chamine's questionnaire (Chamine, n.d.)in order to estimate the internal consistency reliability of this instrument. We show our result in table 3. As shown, the questionnaire had a good internal consistency, and no item was excluded.

Table 3. Internal consistency of Chamine's internal saboteur questionnaire

\begin{tabular}{|l|l|c|c|}
\hline & \multicolumn{1}{|c|}{ Saboteur } & Number of items & McDonald's Omega coefficient \\
\hline 1 & Hyper-vigilant & 5 & 0.798 \\
\hline 2 & Restless & 5 & 0.673 \\
\hline 3 & Hyper-achiever & 5 & 0.785 \\
\hline 4 & Pleaser & 5 & 0.695 \\
\hline 5 & Stickler & 5 & 0.600 \\
\hline 6 & Victim & 5 & 0.845 \\
\hline 7 & Controller & 5 & 0.732 \\
\hline 8 & Avoider & 5 & 0.629 \\
\hline 9 & Hyper-rational & 5 & 0.693 \\
\hline
\end{tabular}

\subsection{Design and Procedure}

The design of the research is non-experimental, transversal, exploratory. The study involved administering an online questionnaire (Google Forms) in March-April 2021. We distributed the link by email, and the data were collected within five weeks.

Participants were not financially motivated to answer the questionnaire, but they benefited from a profile of their internal saboteurs. Participation was voluntary, with no time limit, ensuring the confidentiality of data and responses.

All the questions were asked in the same order for all respondents. All items were mandatory; partial completion of the questionnaire was not allowed. 


\section{RESULTS}

\subsection{Descriptive Analysis}

We used two instruments to collect our data: the Goodman-Syvantek Job Performance Scale and Chamine's internal saboteur questionnaire. None of them yielded a normal distribution of results (Shapiro-Wilk test of normality, see tables 4 and 5); therefore, we opted for non-parametric tests to analyze our data.

Table 4. Self-perceived work performance, descriptive data

\begin{tabular}{|c|c|c|c|c|}
\hline & Indicator & Task performance & Contextual performance & Performance (total) \\
\hline 1 & $\mathrm{~N}$ & 457 & 457 & 457 \\
\hline & Mean & 30.639 & 22.427 & 53.066 \\
\hline & $\begin{array}{l}\text { Standard } \\
\text { deviation }\end{array}$ & 3.947 & 3.574 & 6.168 \\
\hline 4 & Skewness & -0.803 & -0.336 & -0.446 \\
\hline & $\begin{array}{l}\text { Std. error } \\
\text { skewness }\end{array}$ & 0.114 & 0.114 & 0.114 \\
\hline 6 & Kurtosis & 0.671 & -0.584 & 0.017 \\
\hline 7 & $\begin{array}{l}\text { Std. error } \\
\text { kurtosis }\end{array}$ & 0.228 & 0.228 & 0.228 \\
\hline 8 & $\begin{array}{l}\text { Shapiro- } \\
\text { Wilk p }\end{array}$ & $<.001$ & $<.001$ & $<.001$ \\
\hline 9 & Minimum & 15 & 12 & 33 \\
\hline 10 & Maximum & 36 & 28 & 64 \\
\hline
\end{tabular}

Table 5. Chamine's internal saboteurs, descriptive data

\begin{tabular}{|c|c|c|c|c|c|c|c|c|c|c|}
\hline & Indicator & $\begin{array}{l}\text { Hyper- } \\
\text { vigilant }\end{array}$ & Restless & Avoider & Pleaser & Controller & $\begin{array}{c}\text { Hyper- } \\
\text { achiever }\end{array}$ & $\begin{array}{c}\text { Hyper- } \\
\text { rational }\end{array}$ & Stickler & Victim \\
\hline 1 & $\mathrm{~N}$ & 457 & 457 & 457 & 457 & 457 & 457 & 457 & 457 & 457 \\
\hline 2 & Mean & 16.372 & 14.825 & 14.875 & 16.991 & 17.015 & 18.659 & 16.98 & 17.407 & 14.409 \\
\hline 3 & $\begin{array}{l}\text { Standard } \\
\text { deviation }\end{array}$ & 4.786 & 4.033 & 4.155 & 3.964 & 4.073 & 4.111 & 3.918 & 3.565 & 5.244 \\
\hline 4 & Skewness & -0.271 & 0.053 & 0.08 & -0.109 & -0.118 & -0.683 & -0.194 & -0.172 & 0.094 \\
\hline 5 & $\begin{array}{l}\text { Std. error } \\
\text { skewness }\end{array}$ & 0.114 & 0.114 & 0.114 & 0.114 & 0.114 & 0.114 & 0.114 & 0.114 & 0.114 \\
\hline 6 & Kurtosis & -0.613 & -0.38 & -0.558 & -0.308 & -0.555 & 0.209 & -0.025 & -0.229 & -0.859 \\
\hline 7 & $\begin{array}{l}\text { Std. error } \\
\text { kurtosis }\end{array}$ & 0.228 & 0.228 & 0.228 & 0.228 & 0.228 & 0.228 & 0.228 & 0.228 & 0.228 \\
\hline 8 & $\begin{array}{l}\text { Shapiro- } \\
\text { Wilk p }\end{array}$ & $<.001$ & 0.004 & $<.001$ & $<.001$ & $<.001$ & $<.001$ & $<.001$ & $<.001$ & $<.001$ \\
\hline 9 & Minimum & 5 & 5 & 5 & 5 & 7 & 5 & 5 & 5 & 5 \\
\hline 10 & Maximum & 25 & 25 & 25 & 25 & 25 & 25 & 25 & 25 & 25 \\
\hline
\end{tabular}

\subsection{Hypothesis Testing}

\subsubsection{Hypothesis 1}

There is a positive correlation between the strengths of the four internal saboteurs which are oriented toward the accomplishment of objectives (Controller, Hyper-ambitious, Stickler and Hyper-rational) and work performance. 
Table 6. Relationship between performance-oriented saboteurs and work performance, using Spearman's coefficient of correlation

\begin{tabular}{|c|c|c|c|c|}
\hline & Internal saboteur & Performance (total) & Contextual performance & Task performance \\
\hline 1 & Controller & $\begin{array}{c}0.191 \\
\mathrm{p}<0.001\end{array}$ & $\begin{array}{c}0.136 \\
\mathrm{p}=0.004\end{array}$ & $\begin{array}{c}0.189 \\
\mathrm{p}<0.001\end{array}$ \\
\hline 2 & Hyper-ambitious & $\begin{aligned} 0.321 \\
\mathrm{p}<0.001\end{aligned}$ & $\begin{aligned} & 0.210 \\
\mathrm{p} & <0.001\end{aligned}$ & $\begin{array}{c}0.337 \\
\mathrm{p}<0.001\end{array}$ \\
\hline 3 & Stickler & $\begin{array}{c}0.136 \\
p=0.004\end{array}$ & $\begin{array}{c}0.096 \\
p=0.041\end{array}$ & $\begin{array}{c}0.145 \\
p=0.002\end{array}$ \\
\hline 4 & Hyper-rational & $\begin{array}{c}0.231 \\
p<0.001\end{array}$ & $\begin{array}{c}0.177 \\
p<0.001\end{array}$ & $\begin{array}{c}0.199 \\
p<0.001\end{array}$ \\
\hline
\end{tabular}

As it can be seen in table 6, all four performance-oriented saboteurs show a statistically significant positive correlation with work performance, although the Stickler and the Controller seem to correlate rather weakly to both task performance and contextual performance, as well as to total performance. Hypothesis 1 has been verified.

4.2.2. Hypothesis 2

There is a negative correlation between the strengths of the five emotional saboteurs (Victim, Avoider, Hyper-vigilant, Restless, Pleaser) and work performance.

Table 7. Relationship between emotional saboteurs and work performance, using Spearman's coefficient of correlation

\begin{tabular}{|c|c|c|c|c|}
\hline & Internal saboteur & Performance (total) & $\begin{array}{l}\text { Contextual } \\
\text { performance }\end{array}$ & Task performance \\
\hline 1 & Victim & $\begin{array}{c}-0.213 \\
p<0.001\end{array}$ & $\begin{array}{c}-0.056 \\
p=0.233\end{array}$ & $\begin{array}{c}-0.295 \\
p<0.001\end{array}$ \\
\hline 2 & Avoider & $\begin{array}{c}-0.122 \\
p=0.009\end{array}$ & $\begin{array}{c}0.027 \\
p=0.559\end{array}$ & $\begin{array}{c}-0.242 \\
p<0.001\end{array}$ \\
\hline 3 & Pleaser & $\begin{array}{c}0.213 \\
p<0.001\end{array}$ & $\begin{array}{c}0.277 \\
p<0.001\end{array}$ & $\begin{array}{c}0.06 \\
p=0.203\end{array}$ \\
\hline 4 & Hyper-vigilant & $\begin{array}{c}-0.057 \\
p=0.220\end{array}$ & $\begin{array}{c}0.008 \\
p=0.867\end{array}$ & $\begin{array}{c}-0.103 \\
p=0.028\end{array}$ \\
\hline 5 & Restless & $\begin{array}{c}0.012 \\
p=0.804\end{array}$ & $\begin{array}{c}0.118 \\
p=0.012\end{array}$ & $\begin{array}{c}-0.103 \\
p=0.028\end{array}$ \\
\hline
\end{tabular}

As shown in table 7, the emotional saboteurs provide a more varied landscape. Some of them seem to correlate negatively with task performance, such as the Hyper-vigilant, the Restless, the Victim and the Avoider. Others show a positive correlation with contextual performance only, such as the Pleaser. Interestingly, the Restless shows a positive correlation with contextual performance but a negative correlation with task performance. Thus, Hypothesis 2 had been verified only for three out of five emotional saboteurs.

\subsubsection{Hypothesis 3}

Some of the internal saboteurs (Controller, Hyper-achiever, Stickler and Hyper-rational) tend to be stronger in men than in women, while other saboteurs (Victim, Avoider, Pleaser, Restless and Hyper-vigilant) tend to be stronger in women than in men. Because we wanted to assess the distribution of the two clusters of saboteurs across the two genders, we used the Mann-Whitney U test, as shown in table 8. The difference according to gender was significant for the Pleaser, Victim, Controller, Avoider, the Hyper-rational and the Hyper-vigilant. The Stickler, the Restless and the 
Hyper-ambitious showed no significant gender difference. Table 9 shows the descriptive data for the gender distribution of the saboteurs for which gender differences were encountered.

Table 8. Mann-Whitney $U$ test - internal saboteurs according to gender

\begin{tabular}{|c|l|c|c|c|}
\hline & \multicolumn{1}{|c|}{ Internal saboteur } & Mann-Whitney U & $\mathbf{p}$ & Rank biserial correlation \\
\hline 1 & Hyper-ambitious & 19.451 & 0.686 & 0.026 \\
\hline 2 & Pleaser * & $16,610.5$ & 0.050 & -0.124 \\
\hline 3 & Victim * & 12.869 & $<0.001$ & -0.321 \\
\hline 4 & Controller * & 21.621 .5 & 0.027 & 0.14 \\
\hline 5 & Avoider * & 15.139 .5 & 0.001 & -0.202 \\
\hline 6 & Hyper-rational * & 22.859 .5 & 0.001 & 0.205 \\
\hline 7 & Hyper-vigilant * & 15.270 & 0.002 & -0.195 \\
\hline 8 & Restless & 17.561 .5 & 0.242 & -0.074 \\
\hline 9 & Stickler & 17.755 & 0.313 & -0.064 \\
\hline
\end{tabular}

Table 9. Internal saboteurs according to gender, descriptive data

\begin{tabular}{|c|c|c|c|c|c|c|}
\hline & Internal saboteur & Gender & Participants & Average & Standard deviation & Standard error \\
\hline \multirow{2}{*}{1} & \multirow{2}{*}{ Pleaser } & Female $*$ & 348 & 17.17 & 4.038 & 0.216 \\
\hline & & Male & 109 & 16.422 & 3.68 & 0.352 \\
\hline \multirow{2}{*}{2} & \multirow{2}{*}{ Victim } & Female * & 348 & 15.08 & 5.107 & 0.274 \\
\hline & & Male & 109 & 12.266 & 5.12 & 0.49 \\
\hline \multirow{2}{*}{3} & \multirow{2}{*}{ Controller } & Female & 348 & 16.761 & 4.082 & 0.219 \\
\hline & & Male * & 109 & 17.826 & 3.955 & 0.379 \\
\hline \multirow{2}{*}{4} & \multirow{2}{*}{ Avoider } & Female * & 348 & 15.233 & 4.074 & 0.218 \\
\hline & & Male & 109 & 13.734 & 4.224 & 0.405 \\
\hline \multirow{2}{*}{5} & \multirow{2}{*}{ Hyper-rational } & Female & 348 & 16.626 & 3.909 & 0.21 \\
\hline & & Male * & 109 & 18.11 & 3.745 & 0.359 \\
\hline \multirow{2}{*}{6} & \multirow{2}{*}{ Hyper-vigilant } & Female * & 348 & 16.764 & 4.716 & 0.253 \\
\hline & & Male & 109 & 15.119 & 4.815 & 0.461 \\
\hline
\end{tabular}

Perhaps unsurprisingly, male respondents scored higher for the Controller and the Hyper-rational, while the female respondents scored higher for the Victim, the Avoider, the Hyper-vigilant and the Pleaser. The highest biserial correlation coefficient was found between the Victim and the female gender. Interestingly, there was no significant gender difference for the Hyper-Ambitious, the Restless and the Stickler.

\section{DISCUSSION AND CONCLUSIONS}

Results of our research indicate the existence of two clusters of saboteurs, one oriented largely toward emotion and the other oriented largely toward performance, which seemed to align fairly well with the traditional female and male gender, respectively. A future study could take into account a principal component analysis to confirm this hypothesis.

One interesting finding was that the Hyper-ambitious saboteur was found in both genders equally and this is one internal saboteur that is positively correlated with performance.

All findings could be integrated into high-performance HR practices, as there are implications with respect to recruitment and selection, assessment processes, the way organization defines employment security, the proper level of teamwork, the proper ways to measure the employee involvement, etc. 
There were several limitations in this study. Perhaps the most important was that it relied on selfassessment, which is a cognitive act presumably significantly influenced by those very same internal saboteurs being studied. Thus, for example the hyper-achiever might underestimate his or her job performance. However, even if this is a limitation in terms of research, in terms of implications in HRM practices, the situation is different, as it is useful information that might be added to the self-assessment instruments used for evaluation or for selection purposes.

Another obvious limitation of this study was that the sample was not truly random; it comprised self-selecting respondents who have the capacity to fill out a Google Form and who are presumably interested in self-development.

The circumstances in which this study was conducted were extraordinary. The psychological impact of the Covid-19 pandemic may have skewed the responses. A future study using the same instruments and the same sample profile may clarify how and to what extent the results obtained in this study are reliable.

\section{REFERENCES}

Allworth, E., \& Hesketh, B. (1999). Construct-oriented biodata: Capturing change-related and contextually relevant future performance. International Journal of Selection and Assessment, 7(2), 97-111. https://doi.org/https://doi.org/10.1111/1468-2389.00110

Austin, J. T., \& Vancouver, J. B. (1996). Goal constructs in psychology: Structure, process, and content. Psychological Bulletin, 120(3), 338-375. https://doi.org/https://doi.org/10.1037/00332909.120.3.338

Bandura, A. (1994). Self-efficacy. In V. S. Ramachaudran (Ed.), Encyclopedia of human behavior, Vol. 4 (pp. 71-81). Academic Press.

Bandura, A. (1995). Self-efficacy in changing societies. Cambridge University Press. https://doi.org/https://doi.org/10.1017/CBO9780511527692

Bandura, A. (2006). Guide for constructing self-efficacy scales. Self-Efficacy Beliefs of Adolescents, $5(1), 307-337$.

Bandura, A., \& Jourden, F. J. (1991). Self-regulatory mechanisms governing the impact of social comparison on complex decision making. Journal of Personality and Social Psychology, 60(6), 941-951. https://doi.org/https://doi.org/10.1037/0022-3514.60.6.941

Borman, W. C., \& Motowidlo, S. J. (1993). Expanding the criterion domain to include elements of contextual performance. In N. Schmitt \& W. C. Borman (Eds.), Personnel Selection in Organizations (pp. 71-98). Jossey Bass.

Campbell, J. P. (1990). Modeling the performance prediction problem in industrial and organizational psychology. In M., D. Dunnette \& L., M. Hough (Eds.), Handbook of industrial and organizational psychology (pp. 687-732). Consulting Psychologists Press.

Chamine, S. (n.d.). 9 Ways We Self Sabotage - Assessment overview. Retrieved November 18, 2020, from https://assessment.positiveintelligence.com/saboteur/overview

Chamine, S. (2012). Positive Intelligence: Why Only 20\% of Teams and Individuals Achieve Their True Potential and How You Can Achieve Yours. Greenleaf Book Group Press.

Charbonnier-Voirin, A., \& Roussel, P. (2012). Adaptive performance: A new scale to measure individual performance in organizations. Canadian Journal of Administrative Sciences, 29(3), 280-293. https://doi.org/10.1002/CJAS.232

Deng, L., \& Chan, W. (2017). Testing the Difference Between Reliability Coefficients Alpha and Omega. Educational and Psychological Measurement, 77(2), 185-203. https://doi.org/10.1177/0013164416658325

Djabatey, E. N. (2012). Recruitment and selection practices of organizations: A case study of HFC 
Bank (GH) Ltd. Unpublished thesis submitted to the Institute of Distance Learning, Kwame Nkrumah University of Science and Technology. Kwame Nkrumah University of Science and Technology. Retrieved February 12, 2021, from http://citeseerx.ist.psu.edu/viewdoc/download?doi=10.1.1.825.1985\&rep=rep1\&type=pdf

Ekwoaba, J. O., Ikeije, U. U., \& Ufoma, N. (2015). The impact of recruitment and selection criteria on organizational performance. Global Journal of Human Resource Management, 3(2), 22-33. https://doi.org/10.1017/CBO9781107415324.004

Gardner, H. (1983). Frames of mind: The theory of multiple intelligences. Basic Books.

Goodman, S. A., \& Svyantek, D. J. (1999). Person-organization fit and contextual performance: Do shared values matter. Journal of Vocational Behavior, 55, 254-275. https://doi.org/https://doi.org/10.1006/jvbe.1998.1682

Griffin, M. A., Neil, A., \& Parker, S. K. (2007). A new model of work role performance: Positive behavior in uncertain and interdependent contexts. Academy of Management Journal, 50(2), $327-347$.

Guest, D. (2002). Human Resource Management, Corporate Performance and Employee Wellbeing: Building the Worker into HRM. The Journal of Industrial Relations, 44(3), 335-358.

Hayes, A. F., \& Coutts, J. J. (2020). Use Omega Rather than Cronbach's Alpha for Estimating Reliability. But... Communication Methods and Measures, 1-24. https://doi.org/10.1080/19312458.2020.1718629

Iliescu, D. (n.d.). Scala Evaluării Performanței a lui Goodman și Svyantek. Retrieved October 22, 2020, from http://researchcentral.ro/index.php?action=listateste\&ID=430

Koopmans, L., Bernaards, C. M., Hildebrandt, V. H., De Vet, H. C. W., \& Van Der Beek, A. J. (2014). Construct validity of the Individual Work Performance Questionnaire. Journal of Occupational and Environmental Medicine, 56(3), 331-337. https://doi.org/10.1097/JOM.0000000000000113

Koopmans, L., Bernaards, C. M., Hildebrandt, V. H., Schaufeli, W. B., De Vet, H. C. W. \& Van Der Beek, A. J. (2011). Conceptual frameworks of individual work performance: A systematic review. Journal of Occupational and Environmental Medicine, 53(8), 856-866. https://doi.org/10.1097/JOM.0b013e318226a763

Luszczynska, A., Scholz, U. \& Schwarzer, R. (2005). The General Self-Efficacy Scale: Multicultural Validation Studies. The Journal of Psychology, 139, 439-457. https://doi.org/10.3200/JRLP.139.5.439-457

Mostafa, A. M. S. (2017). High-performance HR practices, positive affect and employee outcomes. Journal of Managerial Psychology, 32(2), 163-176. https://doi.org/10.1108/JMP-06-20160177

Murphy, K. R. (1989). Dimensions of job performance. In R. F. Dillon \& J. W. Pellegrino (Eds.), Testing: Theoretical and applied perspectives (pp. 218-247). Praeger Publishers.

Pagán-Castaño, E., Maseda-Moreno, A., \& Santos-Rojo, C. (2020). Wellbeing in work environments. Journal of Business Research, December. https://doi.org/10.1016/j.jbusres.2019.12.007

Panc, T., Mihalcea, A., \& Panc, I. (2012). Self-Efficacy Survey: a new assessment tool. ProcediaSocial and Behavioral Sciences, 33, 880-884.

Powers, W. T. (1991). Commentary on Bandura's "Human Agency." American Psychologist, 46(2), 151-153. https://doi.org/https://doi.org/10.1037/0003-066X.46.2.151.b

Radu, C., Deaconu, A., Mișu, S., \& Triculescu, M. (2020). The Impact of Work Investment on Performance. Amfiteatru Economic, 22(14), 1103-1120.

Rașcă, L., Deaconu, A., \& True, S. (2018). From Successful SMEs to Entrepreneurial Society and 
the Importance of the Entrepreneurial Mindset. In A. M. Dima (Ed.), Doing Business in Europe. Economic Integration Processes, Policies, and the Business Environment (pp. 315328). Springer.

Ravinder, E. B., \& Saraswathi, A. B. (2020). Literature Review Of Cronbach alpha coefficient (A) and Mcdonald' s Omega Coefficient $(\Omega)$. European Journal of Molecular \& Clinical Medicine, 7(6), 2943-2949.

Schwarzer, R., \& Jerusalem, M. (1995). Generalized Self-Efficacy scale. In J. Weinman, S. Wright, \& M. Johnston (Eds.), Measures in health psychology: A user's portfolio. Causal and control beliefs (pp. 35-37). NFER-NELSON.

Sinclair, R. R., \& Tucker, J. S. (2006). Stress-CARE: An Integrated Model of Individual Differences in Soldier Performance under Stress. In T. W. Britt, C. A. Castro, \& A. B. Adler (Eds.), Military Performance. Military life: The psychology of serving in peace and combat: Military performance (pp. 202-231). Praeger Security International.

Stangel, L. (2017). Shirzad Chamine: Five Strategies to Challenge Negative Thoughts. Stanford Graduate School of Business. Retrieved February 25, 2021, from https://www.gsb.stanford.edu/insights/shirzad-chamine-five-strategies-challenge-negativethoughts

Stone, D. N. (1994). Overconfidence in Initial Self-Efficacy Judgments: Effects on Decision Processes and Performance. Organizational Behavior and Human Decision Processes, 59(3), 452-474. https://doi.org/https://doi.org/10.1006/obhd.1994.1069

Tangen, S. (2005). Improving the performance of a performance measure. Measuring Business Excellence, 9(2), 4-11. https://doi.org/10.1108/13683040510602830

Theriou, G. N., \& Chatzoglou, P. (2014). The impact of best HRM practices on performance identifying enabling factors. Employee Relations, 36(5), 535-561. https://doi.org/10.1108/ER02-2013-0025

Tucker, J. S., Sinclair, R. R., Mohr, C. D., Adler, A. B., Thomas, J. L., \& Salvi, A. D. (2009). Stress and Counterproductive Work Behavior: Multiple Relationships Between Demands, Control, and Soldier Indiscipline Over Time. Journal of Occupational Health Psychology, 14(3), 257271. https://doi.org/10.1037/a0014951

Vancouver, J. B., Thompson, C. M., Tischner, E. C., \& Putka, D. J. (2002). Two studies examining the negative effect of self-efficacy on performance. Journal of Applied Psychology, 87(3), 506516. https://doi.org/10.1037/0021-9010.87.3.506

Vancouver, J. B., Thompson, C. M., \& Williams, A. A. (2001). The changing signs in the relationships among self-efficacy, personal goals, and performance. Journal of Applied Psychology, 86(4), 605-620. https://doi.org/10.1037/0021-9010.86.4.605

Whitener, E. M. (2001). Do "high commitment" human resource practices affect employee commitment? A cross-level analysis using hierarchical linear modeling Ellen. Journal of Management, 27(5), 515-535. https://doi.org/10.1177/014920630102700502 